\title{
Changes in the Prosthesis Types Used for Aortic Valve Replacement after the Introduction of Sutureless and Rapid Deployment Valves in Korea: A Nationwide Population-Based Cohort Study
}

\author{
Hyeok Sang Woo, M.D. ${ }^{1}$, Ho Young Hwang, M.D., Ph.D. ${ }^{,}$, Ho Jin Kim, M.D. ${ }^{2}$, Joon Bum Kim, M.D., Ph.D. ${ }^{2}$, \\ Sak Lee, M.D., Ph.D. ${ }^{3}$, Cheong Lim, M.D., Ph.D. ${ }^{4}$, Byung-Cheul Chang, M.D., Ph.D. ${ }^{5}$, Na Rae Lee, Ph.D. ${ }^{6}$, \\ Youshin Suh, M.S. ${ }^{6}$, Jae Woong Choi, M.D., Ph.D.'
}

'Department of Thoracic and Cardiovascular Surgery, Seoul National University Hospital; ${ }^{2}$ Department of Thoracic and Cardiovascular Surgery, Asan Medical

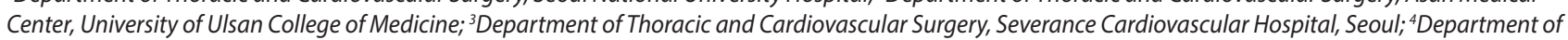
Thoracic and Cardiovascular Surgery, Seoul National University Bundang Hospital, Seoul National University College of Medicine; ${ }^{5}$ Department of Thoracic and Cardiovascular Surgery, CHA Bundang Medical Center, CHA University, Seongnam; ${ }^{6}$ National Evidence-based Healthcare Collaborating Agency, Seoul, Korea

\section{ARTICLE INFO}

Received April 23, 2021

Revised June 26, 2021

Accepted July 14, 2021

Corresponding author

Jae Woong Choi

Tel $82-2-2072-4069$

Fax 82-2-762-3566

E-mail woong3537@hanmail.net

ORCID

https://orcid.org/0000-0002-0921-756X

\begin{abstract}
Background: Sutureless and rapid deployment valves for aortic valve replacement (AVR) were introduced in Korea in December 2016. This study evaluated changing trends in the prosthetic valves used for AVR in Korea after the introduction of sutureless and rapid deployment valves.

Methods: From December 2016 to December 2018, 4,899 patients underwent AVR in Korea. After applying the exclusion criteria, 4,872 patients were analyzed to determine changes in the type of prosthetic valve used for AVR. The study period was divided into 5 groups corresponding to 5-month intervals.

Results: The total number of AVR cases was $194.88 \pm 28.78$ per month during the study period. Mechanical valves were used in approximately $27 \%$ to $33 \%$ of cases, and the proportion of mechanical valve use showed a tendency to decrease, with marginal significance overall ( $p=0.078$ ) and significant decreases in patients less than 60 years of age and in men $(p=0.013$ and $p=0.023$, respectively). The use of sutureless valves increased from $13.4 \%$ to $25.8 \%$ of cases ( $p<0.001$ ), especially in elderly patients ( $>70$ years) and those requiring concomitant surgery. In a comparison between sutureless and rapid deployment valves, the use of Perceval S valves (a type of sutureless valve), gradually increased ( $p<0.001)$.

Conclusion: After the introduction of sutureless and rapid deployment valves in Korea, the rate of use of these new valves remarkably increased, especially in elderly patients and those requiring concomitant surgery. Further studies should investigate the clinical outcomes of these new prostheses.
\end{abstract}

Keywords: Aortic valve surgery, Korea, Rapid deployment valve, Sutureless valve, Trends

\section{Introduction}

Although surgical aortic valve replacement (AVR) is the standard treatment for aortic valve disease, there have been some limitations in applying conventional AVR in all patients. Recently, transcatheter aortic valve implantation has been used for intermediate- and high-risk patients $[1,2]$, and sutureless (or rapid deployment) AVR (SuAVR) has also gained attention as a new alternative option for highrisk patients [3-5].

SuAVR involves a short aortic cross-clamp (ACC) time, since suture placement is not required, and enables straightforward implantation in limited surgical fields [6]. Currently, 2 types of sutureless aortic valves are available: The Edwards Intuity Elite valve system (Intuity valve; Edwards Lifesciences, Irvine, CA, USA) and the Perceval S 
valve (Perceval valve; LivaNova, London, UK). The Intuity valve system obtained the Conformité Européenne (CE) mark in 2012, and received Food and Drug Administration (FDA) approval in 2016 [7]. The Perceval valve obtained the CE mark and received FDA approval in 2011 and 2016, respectively [8]. In Korea, interest in sutureless valve systems has increased since December 2016, when the Korean National Health Insurance Service (NHIS) began covering these valves.

Several other studies have explored national trends in valve use for AVR; the frequency of using mechanical valves has decreased, and the use of bioprosthetic valves has increased [9-13]. However, there are few studies with relatively recent national data on valve use for AVR surgery. In particular, limited data have been reported on national trends in the types of prosthetic valves used for AVR since sutureless valves were introduced. Therefore, this study aimed to analyze the changing trends in the types of valves used in Korea after the introduction of the sutureless aortic valve.

\section{Methods}

\section{Data source and patient characteristics}

Data for the present study was obtained from the claims database of the Korean NHIS, which is a single insurer covering the entire Korean population that is managed by the government. The NHIS provides healthcare insurance coverage to the vast majority $(>97 \%)$ of residents in Korea $[14,15]$. From December 2016, when SuAVR was approved for insurance coverage, to December 2018, 4,899 patients who underwent AVR using conventional prosthetic valves or sutureless aortic prostheses were identified based on the procedure codes of the Korean NHIS (O1793: aortic valve replacement, O1799: sutureless aortic valve replacement). Excluding 23 patients who were under the age of 19 and 4 patients for whom age data were not available, a total of 4,872 patients were enrolled in this study (Table 1 ).

The patients were divided into 4 groups according to age (19-59, 60-69, 70-79, and 80 years or older). There were 1,114 patients (22.9\%) aged $19-59,1,434$ patients $(29.4 \%)$ aged $60-69,1,774$ patients (36.4\%) aged 70-79, and 550 patients (11.3\%) aged 80 or older. Combined surgery was de-

Table 1. Patient characteristics

\begin{tabular}{|c|c|c|c|c|}
\hline Characteristic & Total $(n=4,872)$ & $\begin{array}{l}\text { Mechanical valve } \\
\qquad(n=1,493)\end{array}$ & $\begin{array}{l}\text { Bioprosthetic valve } \\
\qquad(n=3,379)\end{array}$ & $\mathrm{p}$-value \\
\hline \multicolumn{5}{|l|}{ Age (yr) } \\
\hline $19-59$ & $1,114(22.9)$ & $927(62.1)$ & $187(5.5)$ & $<0.001$ \\
\hline $60-69$ & $1,434(29.4)$ & $505(33.8)$ & $929(27.5)$ & $<0.001$ \\
\hline $70-79$ & $1,774(36.4)$ & $58(3.9)$ & $1,716(50.8)$ & $<0.001$ \\
\hline$>80$ & $550(11.3)$ & $3(0.2)$ & $547(16.2)$ & $<0.001$ \\
\hline Male & $2,800(57.4)$ & $936(62.7)$ & $1,864(55.2)$ & $<0.001$ \\
\hline Combined operation & $2,250(46.2)$ & $789(52.8)$ & $1,461(43.2)$ & $<0.001$ \\
\hline Tricuspid valve & $417(8.6)$ & $190(12.7)$ & $227(6.7)$ & $<0.001$ \\
\hline Mitral valve & $847(17.4)$ & $409(27.4)$ & $438(13.0)$ & $<0.001$ \\
\hline Arrhythmia & $534(11.0)$ & $229(15.3)$ & $305(9.0)$ & $<0.001$ \\
\hline Aorta & $774(15.9)$ & $260(17.4)$ & $514(15.2)$ & 0.052 \\
\hline Coronary artery bypass grafting & $645(13.2)$ & $108(7.2)$ & $537(15.9)$ & $<0.001$ \\
\hline \multicolumn{5}{|l|}{ History of diseases } \\
\hline Cancer & $537(11.0)$ & $106(7.1)$ & $431(12.8)$ & $<0.001$ \\
\hline Hypertension & 4,076 (83.7) & $1,138(76.2)$ & $2,938(86.9)$ & $<0.001$ \\
\hline Dyslipidemia & $3,548(72.8)$ & $959(64.2)$ & $2,589(76.6)$ & $<0.001$ \\
\hline Chronic obstructive pulmonary disease & $2,358(48.4)$ & $625(41.9)$ & $1,733(51.3)$ & $<0.001$ \\
\hline Cerebrovascular disease & $1,054(21.6)$ & $221(14.8)$ & $833(24.7)$ & $<0.001$ \\
\hline Peripheral vascular disease & $1,587(32.6)$ & $398(26.7)$ & $1,189(35.2)$ & $<0.001$ \\
\hline Kidney disease & $946(19.4)$ & $252(16.9)$ & $694(20.5)$ & 0.003 \\
\hline Congestive heart failure & $2,633(54.0)$ & $768(51.4)$ & $1,865(55.2)$ & 0.015 \\
\hline Diabetes mellitus & $2,243(46.0)$ & $601(40.3)$ & $1,642(48.6)$ & $<0.001$ \\
\hline Liver disease & $1,388(28.5)$ & $410(27.5)$ & $978(28.9)$ & 0.291 \\
\hline
\end{tabular}

Values are presented as number (\%). 
fined as the concomitant presence of the appropriate treatment code for tricuspid valve surgery, mitral valve surgery, arrhythmia surgery, aortic surgery, and coronary artery bypass grafting. A combined operation was performed in 2,250 patients $(46.2 \%)$, including mitral valve surgery $(\mathrm{n}=847,17.4 \%)$ and aorta surgery $(\mathrm{n}=774,15.7 \%)$. To evaluate trends in the use of specific prosthetic valve types, the study period was divided into 5 groups corresponding to 5-month intervals.

\section{Statistical analysis}

Statistical analyses were performed using IBM SPSS ver. 26.0 (IBM Corp., Armonk, NY, USA). Data were expressed as the mean \pm standard deviation or proportions. The Kolmogorov-Smirnov test was used to confirm the normality of the test data. The chi-square test or Fisher exact test for categorical variables and the Student t-test for continuous variables were used to make comparisons between the 2 groups. The number of samples was too small to perform normality testing by period, so normality testing was conducted by month. The Cochran-Armitage test was used to analyze trends in the proportion of prosthetic valves used. A p-value $<0.05$ was used as the threshold for statistical significance, and a $p$-value $\geq 0.05$ but $<0.1$ was considered to indicate marginal significance.

This study was reviewed and approved by the Institutional Review Board of the National Evidence-based Healthcare Collaborating Agency (approval no., NECA IRB 19-006). The requirement for informed consent from individual patients was omitted since it was to be conduct- ed on existing anonymous data from previous years.

\section{Results}

\section{Overall trends of aortic valve replacement by prosthesis valve type}

Fig. 1 shows the monthly trends in the types of prosthesis valves used for AVR for 25 months. Among the 4,872 patients, 1,493 patients (30.6\%) underwent AVR with a mechanical valve and 3,379 patients (69.4\%) underwent AVR with a bioprosthetic valve. The number of total AVR cases per month was $194.88 \pm 28.78$. The numbers of bioprosthetic and mechanical AVR cases were 135.16 \pm 22.19 and $59.72 \pm 11.16$, respectively. In groups divided into 5 -month period, although the number of AVR procedures decreased from 1,006 cases $(20.6 \%)$ in the first period to 901 cases $(18.5 \%)$ in the last period, there was no significant change in the total number of AVR cases $(p=0.20)$. Mechanical valves were used in $27 \%$ to $33 \%$ of cases, and the proportion of mechanical valves showed a tendency to decrease with marginal significance $(\mathrm{p}=0.078)$ (Table 2, Fig. 2).

For the groups divided by age, the use of mechanical valves significantly decreased in patients $<60$ years of age $(p=0.013)$, whereas there were no significant changes in the proportion of cases that used mechanical or bioprosthetic valves in patients who were $\geq 60$ years of age (Table 2 ). The proportion of mechanical valves used in men ranged from $29 \%$ to $37 \%$, and the proportion significantly decreased throughout the study period $(\mathrm{p}=0.023)$ (Table 2$)$.

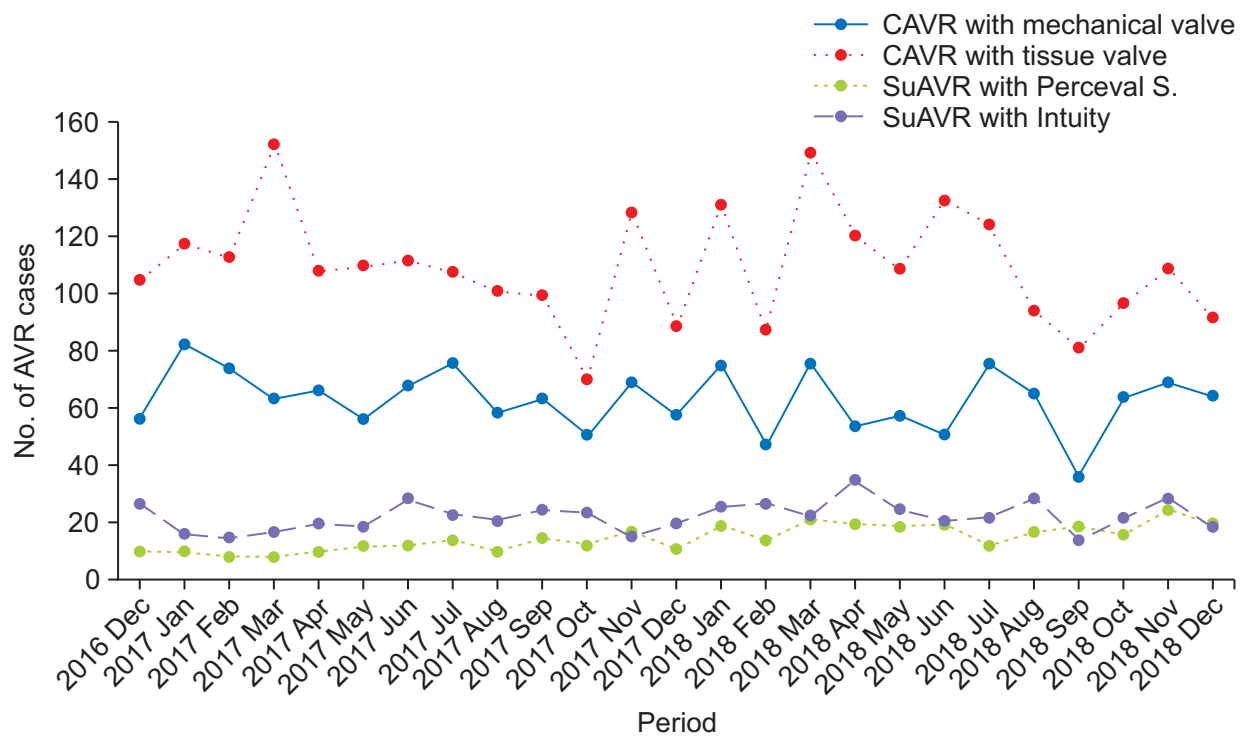

Fig. 1. Number of aortic valve replacement (AVR) procedures according to valve type. CAVR, conventional aortic valve replacement; SuAVR, sutureless (or rapid deployment) aortic valve replacement. 
Table 2. Trends in prosthetic valve types in aortic valve replacement

\begin{tabular}{|c|c|c|c|c|c|c|c|}
\hline Variable & Total & $\begin{array}{l}\text { Dec 2016- } \\
\text { Apr } 2017\end{array}$ & $\begin{array}{c}\text { May 2017- } \\
\text { Sep } 2017\end{array}$ & $\begin{array}{l}\text { Oct 2017- } \\
\text { Feb } 2018\end{array}$ & $\begin{array}{c}\text { Mar 2018- } \\
\text { Jul } 2018\end{array}$ & $\begin{array}{l}\text { Aug 2018- } \\
\text { Dec } 2018\end{array}$ & $\mathrm{p}$-value \\
\hline \multicolumn{8}{|l|}{ Total $(n=4,872)$} \\
\hline Overall & $4,872(100.0)$ & 1,006 (20.6) & $956(19.6)$ & $912(18.7)$ & $1,097(22.5)$ & $901(18.5)$ & $0.200^{\mathrm{a})}$ \\
\hline Mechanical valve & $1,493(30.6)$ & 327 (32.5) & $306(32.0)$ & $282(30.9)$ & $297(27.1)$ & $281(31.2)$ & 0.078 \\
\hline Bioprosthetic valve & & $679(67.5)$ & $650(68.0)$ & $630(69.1)$ & $800(72.9)$ & $620(68.8)$ & \\
\hline Male $(n=2,800)$ & $3,379(69.4)$ & & & & & & 0.023 \\
\hline Mechanical valve & $936(33.4)$ & $206(35.2)$ & $206(37.4)$ & $172(33.9)$ & $184(28.8)$ & $168(32.6)$ & \\
\hline Bioprosthetic valve & & $380(64.8)$ & $345(62.6)$ & $336(66.1)$ & $456(71.3)$ & $347(67.4)$ & \\
\hline Age $19-59$ yr $(n=1,114)$ & $1,864(66.6)$ & & & & & & 0.013 \\
\hline Mechanical valve & 927 (83.2) & $193(86.2)$ & $214(87.7)$ & $174(82.1)$ & $178(78.4)$ & $168(81.2)$ & \\
\hline Bioprosthetic valve & & $31(13.8)$ & $30(12.3)$ & 38 (17.9) & 49 (21.6) & $39(18.8)$ & \\
\hline Age $60-69$ yr $(n=1,434)$ & $187(16.8)$ & & & & & & 0.975 \\
\hline Mechanical valve & $505(35.2)$ & $119(40.6)$ & $81(28.5)$ & $97(35.1)$ & $105(33.1)$ & $103(39.0)$ & \\
\hline Bioprosthetic valve & & $174(59.4)$ & $203(71.5)$ & $179(64.9)$ & $212(66.9)$ & $161(61.0)$ & \\
\hline Age $70-79$ yr $(n=1,774)$ & $929(64.8)$ & & & & & & 0.513 \\
\hline Mechanical valve & $58(3.3)$ & $14(3.6)$ & $11(3.3)$ & $11(3.6)$ & $12(2.9)$ & $10(2.9)$ & \\
\hline Bioprosthetic valve & & $373(96.4)$ & $319(96.7)$ & $291(96.4)$ & $402(97.1)$ & $331(97.1)$ & \\
\hline Age $>80$ yr $(n=550)$ & $1,716(96.7)$ & & & & & & 0.972 \\
\hline Mechanical valve & $3(0.5)$ & $1(1.0)$ & 0 & 0 & $2(1.4)$ & 0 & \\
\hline Bioprosthetic valve & 547 (99.5) & $101(99.0)$ & $98(100.0)$ & $122(100.0)$ & 137 (98.6) & $89(100.0)$ & \\
\hline
\end{tabular}

Values are presented as number (\%).

${ }^{a)} p$-values of normality testing for the overall number of aortic valve replacement procedures were calculated monthly, not periodically.

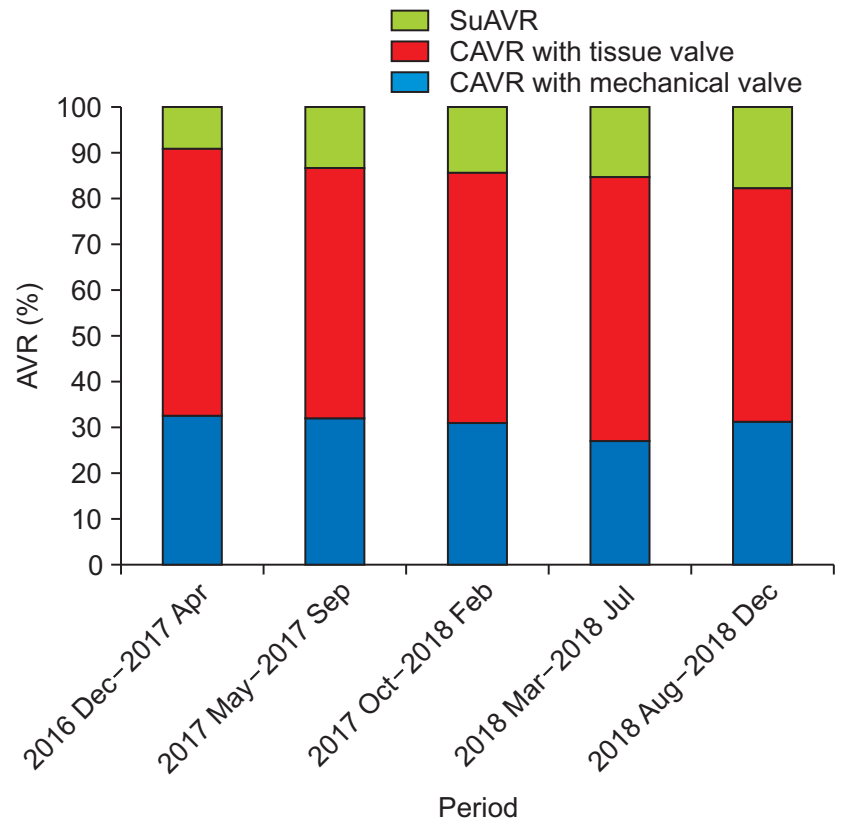

Fig. 2. Proportion of aortic valve replacements (AVRs) in 5-month periods according to valve type. CAVR, conventional aortic valve replacement; SuAVR, sutureless (or rapid deployment) aortic valve replacement.

\section{Trends of sutureless valve utilization}

Among the 3,379 patients who underwent AVR with a bioprosthetic valve, 686 patients (20.3\%) underwent sutureless AVR. Intuity valves were used in 439 patients (64.0\%), while Perceval valves were used in 247 patients (36.0\%). Conventional bioprosthetic valves were frequently used in patients aged 60-69 years, patients with liver disease, and patients requiring concomitant surgery. Sutureless valves were preferred in patients over 80 years old (Table 3).

The proportion of sutureless AVR to total bioprosthetic AVR was around $13.4 \%-25.8 \%$ in the groups divided by 5-month period. The proportion of sutureless AVR dramatically increased from $13.4 \%$ in the first period to $25.8 \%$ in the last period $(\mathrm{p}<0.001)$ (Table 4, Fig. 2). The use of Perceval valves significantly increased from $23.1 \%$ to $45.0 \%$, while the use of Intuity valves significantly decreased from $76.9 \%$ to $55.0 \%$ during the study period ( $<<0.001)$.

In the 1,461 patients $(43.2 \%)$ who underwent concomitant procedures, the use of sutureless valves significantly increased from $10.9 \%$ in the first period to $21.8 \%$ in the last period $(p<0.001)$. There were no significant changes in the proportion of the use of sutureless aortic valves in patients $<70$ years of age, but the use of sutureless valves increased significantly in patients $\geq 70$ years of age (Table 4 ). In particular, the use of sutureless valves increased from $18.8 \%$ to $27.4 \%$ in patients who were older than 80 years of age. When comparing the use of the Perceval and Intuity valves, the use of the Perceval valve in patients aged 70-79 
Table 3. Characteristics of patients who received bioprosthetic valves

\begin{tabular}{|c|c|c|c|c|c|c|}
\hline Variable & $\begin{array}{c}\text { Conventional } \\
\text { bioprostheses } \\
\quad(n=2,693)\end{array}$ & $\begin{array}{c}\text { Sutureless or RD } \\
\text { valves }(n=686)\end{array}$ & $\begin{array}{l}\text { Intuity } \\
(\mathrm{n}=439)\end{array}$ & $\begin{array}{l}\text { Perceval } \\
(n=247)\end{array}$ & $\mathrm{p}$-value ${ }^{\mathrm{a})}$ & $p$-value $e^{\text {b) }}$ \\
\hline \multicolumn{7}{|l|}{ Age (yr) } \\
\hline 19-59 & $152(5.6)$ & $35(5.1)$ & $29(6.6)$ & $6(2.4)$ & 0.579 & 0.017 \\
\hline $60-69$ & 766 (28.4) & $163(23.8)$ & $118(26.9)$ & 45 (18.2) & 0.014 & 0.011 \\
\hline $70-79$ & $1,378(51.2)$ & $338(49.3)$ & $201(45.8)$ & $137(55.5)$ & 0.375 & 0.015 \\
\hline$>80$ & $390(14.5)$ & $150(21.9)$ & $91(20.7)$ & 59 (23.9) & $<0.001$ & 0.337 \\
\hline Male & $1,500(55.7)$ & $364(53.1)$ & $246(56.0)$ & $118(47.8)$ & 0.215 & 0.037 \\
\hline Combined operation & $1,221(45.3)$ & $240(35)$ & $165(37.6)$ & 75 (30.4) & $<0.001$ & 0.057 \\
\hline Tricuspid valve & $188(7.0)$ & $39(5.7)$ & $17(3.9)$ & $22(8.9)$ & $<0.001$ & 0.006 \\
\hline Mitral valve & $382(14.2)$ & $56(8.2)$ & $39(8.9)$ & $17(6.9)$ & $<0.001$ & 0.358 \\
\hline Arrhythmia & $260(9.7)$ & $45(6.6)$ & $33(7.5)$ & $12(4.9)$ & 0.012 & 0.177 \\
\hline Aorta & $452(16.8)$ & $62(9.0)$ & $59(13.4)$ & $3(1.2)$ & $<0.001$ & $<0.001$ \\
\hline CABG & $440(16.3)$ & $97(14.1)$ & $55(12.5)$ & $42(17.0)$ & 0.016 & 0.106 \\
\hline \multicolumn{7}{|l|}{ History of diseases } \\
\hline Cancer & $350(13.0)$ & 81 (11.8) & $52(11.8)$ & $29(11.7)$ & 0.405 & 0.968 \\
\hline Hypertension & $2,336(86.7)$ & $602(87.8)$ & $386(87.9)$ & $216(87.4)$ & 0.483 & 0.855 \\
\hline Dyslipidemia & $2,056(76.3)$ & $533(77.7)$ & $346(78.8)$ & $187(75.7)$ & 0.232 & 0.348 \\
\hline COPD & $1,385(51.4)$ & $348(50.7)$ & $216(49.2)$ & $132(53.4)$ & 0.743 & 0.286 \\
\hline Cerebrovascular disease & $651(24.2)$ & $182(26.5)$ & $120(27.3)$ & $62(25.1)$ & 0.201 & 0.525 \\
\hline Peripheral vascular disease & $965(35.8)$ & $224(32.7)$ & $147(33.5)$ & $77(31.2)$ & 0.119 & 0.536 \\
\hline Kidney disease & $558(20.7)$ & $136(19.8)$ & $73(16.6)$ & $63(25.5)$ & 0.604 & 0.005 \\
\hline Congestive heart failure & $1,479(54.9)$ & $386(56.3)$ & $236(53.8)$ & $150(60.7)$ & 0.526 & 0.077 \\
\hline Diabetes mellitus & $1,304(48.4)$ & $338(49.3)$ & $204(46.5)$ & $134(54.3)$ & 0.691 & 0.050 \\
\hline Liver disease & $808(30.0)$ & $170(24.8)$ & $112(25.5)$ & $58(23.5)$ & 0.007 & 0.554 \\
\hline
\end{tabular}

Values are presented as number (\%).

$\mathrm{RD}$, rapid deployment; $\mathrm{CABG}$, coronary artery bypass grafting; COPD, chronic obstructive pulmonary disease.

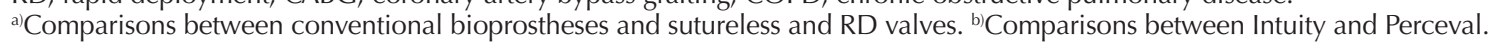

Table 4. Trends in bioprosthetic valves by patient characteristics

\begin{tabular}{|c|c|c|c|c|c|c|c|}
\hline Variable & Total & $\begin{array}{c}\text { Dec } 2016- \\
\text { Apr } 2017\end{array}$ & $\begin{array}{c}\text { May 2017- } \\
\text { Sep } 2017\end{array}$ & $\begin{array}{c}\text { Oct 2017- } \\
\text { Feb } 2018\end{array}$ & $\begin{array}{c}\text { Mar 2018- } \\
\text { Jul } 2018\end{array}$ & $\begin{array}{c}\text { Aug } 2018- \\
\text { Dec } 2018\end{array}$ & p-value \\
\hline Total $(\mathrm{n}=3,379)$ & & & & & & & $<0.001$ \\
\hline Conventional bioprostheses & $2,693(79.7)$ & $588(86.6)$ & $520(80.0)$ & $495(78.6)$ & $630(78.8)$ & $460(74.2)$ & \\
\hline Sutureless or rapid deployment valves & $686(20.3)$ & $91(13.4)$ & $130(20.0)$ & $135(21.4)$ & $170(21.3)$ & $160(25.8)$ & \\
\hline Perceval S & $247(36.0)$ & $21(23.1)$ & $38(29.2)$ & $48(35.6)$ & $68(40.0)$ & $72(45.0)$ & $<0.001$ \\
\hline Intuity & $439(64.0)$ & $70(76.9)$ & $92(70.8)$ & $87(64.4)$ & $102(60.0)$ & $88(55.0)$ & \\
\hline Combined procedure $(n=1,461)$ & & & & & & & $<0.001$ \\
\hline Conventional bioprostheses & $1,221(83.6)$ & $253(89.1)$ & $236(85.5)$ & $229(81.5)$ & $309(83.1)$ & $194(78.2)$ & \\
\hline Sutureless or rapid deployment valves & $240(16.4)$ & $31(10.9)$ & $40(14.5)$ & $52(18.5)$ & $63(16.9)$ & $54(21.8)$ & \\
\hline Age $19-59$ yr $(n=1,114)$ & & & & & & & 0.250 \\
\hline Conventional bioprostheses & $152(81.3)$ & $26(83.9)$ & $25(83.3)$ & $32(84.2)$ & $41(83.7)$ & $28(71.8)$ & \\
\hline Sutureless or rapid deployment valves & $35(18.7)$ & $5(16.1)$ & $5(16.7)$ & $6(15.8)$ & $8(16.3)$ & $11(28.2)$ & \\
\hline Age $60-69$ yr $(n=1,434)$ & & & & & & & 0.287 \\
\hline Conventional bioprostheses & $766(82.5)$ & $151(86.8)$ & $164(80.8)$ & $148(82.7)$ & $171(80.7)$ & $132(82.0)$ & \\
\hline Sutureless or rapid deployment valves & $163(17.5)$ & $23(13.2)$ & $39(19.2)$ & $31(17.3)$ & $41(19.3)$ & $29(18.0)$ & \\
\hline Age $70-79$ yr $(n=1,774)$ & & & & & & & $<0.001$ \\
\hline Conventional bioprostheses & $1,378(80.3)$ & $329(88.2)$ & $258(80.9)$ & $226(77.7)$ & $322(80.1)$ & $243(73.4)$ & \\
\hline Sutureless or rapid deployment valves & $338(19.7)$ & $44(11.8)$ & $61(19.1)$ & $65(22.3)$ & $80(19.9)$ & $88(26.6)$ & \\
\hline Age $>80$ yr $(n=550)$ & & & & & & & 0.007 \\
\hline Conventional bioprostheses & $397(72.6)$ & $82(81.2)$ & $73(74.5)$ & $89(73.0)$ & $96(70.1)$ & $57(64.0)$ & \\
\hline Sutureless or rapid deployment valves & $150(27.4)$ & $19(18.8)$ & $25(25.5)$ & $33(27.0)$ & $41(29.9)$ & $32(36.0)$ & \\
\hline
\end{tabular}

Values are presented as number (\%). 
years $(p=0.007)$ and $\geq 80$ years $(p=0.009)$ showed significant increases.

\section{Discussion}

There were 3 main findings of this study. First, the frequency of using mechanical valves in the aortic position declined. Second, the frequency of using sutureless or rapid deployment aortic valves significantly increased in patients aged $>70$ years or patients who required a concomitant procedure. Third, the frequency of using Perceval valves steadily increased, whereas the proportion of cases using Intuity valves decreased.

During the study period, the frequency of using mechanical valves decreased with marginal significance. In particular, the use of mechanical valves in patients under 60 years of age significantly decreased from $86.2 \%$ to $81.2 \%$. The age criteria for valve selection between mechanical and tissue valves depend on patients' lifestyle and choices, and the indications for using bioprosthetic valves have been expanded [16-21]. The latest guidelines published in 2020 suggested that for patients between 50 and 65 years of age who require AVR, individualizing the choice of a mechanical or bioprosthetic valve prosthesis based on patient factors and after informed shared decision-making would be rational [21]. In addition, improvements in the technology of valve-in-valve transcatheter AVR could increase the number of patients who choose a bioprosthetic valve [22].

This study confirmed that the use of sutureless and rapid deployment valves has gradually increased after these new types of prostheses were introduced in Korea. In particular, the use of sutureless and rapid deployment valves increased remarkably in patients over 70 years of age and those who required concomitant surgery. According to a previous meta-analysis, using a sutureless or rapid deployment valve can reduce the ACC time and cardiopulmonary bypass (CPB) time by approximately 25 minutes [6]. Because prolonged ACC and CPB times are associated with increased morbidity and mortality [23,24], surgeons may prefer to use a sutureless or rapid deployment valve for high-risk patients with other cardiac diseases. Considering the growth of the aging population and increasing demand for minimally invasive surgery, the use of sutureless or rapid deployment valves is expected to increase in the future. In addition, many recent studies have reported good midand long-term clinical outcomes of sutureless and rapid deployment valves in terms of safety, efficacy, hemodynamic performance, and durability $[4,5,25,26]$.
When comparing sutureless (Perceval) valves with rapid deployment (Intuity) valves during the study period, the use of sutureless valves was seen to increase, whereas the use of rapid deployment valves decreased. In the first period, the use of rapid deployment valves was 3.3 times more common than the use of sutureless valves. However, the use of sutureless valves gradually increased and reached a similar level as that of rapid deployment valves in the most recent period. These trends are related to the characteristics of the 2 valves. At first, the rapid deployment valve may seem more familiar to surgeons because the valve is combined with a preexisting valve (Carpentier-Edwards Perimount Magna Ease) with a sub-annular frame and can be inserted through aortotomy, which is usually used for conventional AVR. In the same context, sutureless valves require higher aortotomy, which could be a barrier to inexperienced surgeons. However, the additional benefit of the sutureless valve in high-risk patients who have small sinotubular junctions or aortic root calcification might have contributed to the increased use of this valve.

The present study has several limitations. First, although the surgical approach used depends on the choice of the prosthetic valve type, data on the surgical approach were not analyzed. Second, this study was designed to collect insurance claims data after sutureless valves were introduced to clinical practice. Since data were not collected on the use of prostheses before the introduction of sutureless valves, a comparison of the use of prostheses before and after the introduction of sutureless valves could not be made. Third, although the pathophysiology of the aortic valve (regurgitation or stenosis) and some anatomical factors, such as leaflet status or dilated sinus of Valsalva, are commonly considered in valve selection, this claim data were impossible to obtain; likewise, it was not possible to analyze data related to echocardiography or computed tomography. Therefore, the specific indications of each valve were not considered when analyzing trends in prosthesis use in this study.

\section{Conflict of interest}

No potential conflict of interest relevant to this article was reported.

\section{Funding}

This work was supported by the National Evidence-based Healthcare Collaborating Agency (grant no., NR19-002). 


\section{ORCID}

Hyeok Sang Woo: https://orcid.org/0000-0003-4967-6004

Ho Young Hwang: https://orcid.org/0000-0002-8935-8118

Ho Jin Kim: https://orcid.org/0000-0002-0809-2240

Joon Bum Kim: https://orcid.org/0000-0001-5801-2395

Sak Lee: https://orcid.org/0000-0001-6130-2342

Cheong Lim: https://orcid.org/0000-0003-0913-7014

Byung-Cheul Chang: https://orcid.org/0000-0001-5005-8217

Na Rae Lee: https://orcid.org/0000-0001-6155-9906

Youshin Suh: https://orcid.org/0000-0002-2966-7904

Jae Woong Choi: https://orcid.org/0000-0002-0921-756X

\section{References}

1. Singh K, Bhalla AS, Qutub MA, Carson K, Labinaz M. Systematic review and meta-analysis to compare outcomes between intermediate- and high-risk patients undergoing transcatheter aortic valve implantation. Eur Heart J Qual Care Clin Outcomes 2017;3:289-95.

2. Reardon MJ, van Mieghem NM, Popma JJ, et al. Surgical or transcatheter aortic-valve replacement in intermediate-risk patients. $\mathrm{N}$ Engl J Med 2017;376:1321-31.

3. Folliguet TA, Laborde F, Zannis K, Ghorayeb G, Haverich A, Shrestha M. Sutureless perceval aortic valve replacement: results of two European centers. Ann Thorac Surg 2012;93:1483-8.

4. Szecel D, Eurlings R, Rega F, Verbrugghe P, Meuris B. Perceval sutureless aortic valve implantation: midterm outcomes. Ann Thorac Surg 2021;111:1331-7.

5. Andreas M, Coti I, Rosenhek R, et al. Intermediate-term outcome of 500 consecutive rapid-deployment surgical aortic valve procedures. Eur J Cardiothorac Surg 2019;55:527-33.

6. Hurley ET, O'Sullivan KE, Segurado R, Hurley JP. A meta-analysis examining differences in short-term outcomes between sutureless and conventional aortic valve prostheses. Innovations (Phila) 2015; 10:375-82.

7. D'Onofrio A, Tessari C, Filippini C, et al. Early and mid-term results of rapid deployment valves: the Intuity Italian Registry (INTU-ITA). Ann Thorac Surg 2018;106:1742-9.

8. Concistre G, Chiaramonti F, Bianchi G, et al. Aortic valve replacement with perceval bioprosthesis: single-center experience with 617 implants. Ann Thorac Surg 2018;105:40-6.

9. Abe T, Kumamaru H, Nakano K, Motomura N, Miyata H, Takamoto S. Status of cardiovascular surgery in Japan between 2017 and 2018: a report based on the Japan Cardiovascular Surgery Database: 3. valvular heart surgery. Asian Cardiovasc Thorac Ann 2021;29:300-9.

10. Dunning J, Gao H, Chambers J, et al. Aortic valve surgery: marked increases in volume and significant decreases in mechanical valve use: an analysis of 41,227 patients over 5 years from the Society for Cardiothoracic Surgery in Great Britain and Ireland National Data- base. J Thorac Cardiovasc Surg 2011;142:776-82.

11. Siregar S, de Heer F, Groenwold RH, et al. Trends and outcomes of valve surgery: 16-year results of Netherlands Cardiac Surgery National Database. Eur J Cardiothorac Surg 2014;46:386-97.

12. Isaacs AJ, Shuhaiber J, Salemi A, Isom OW, Sedrakyan A. National trends in utilization and in-hospital outcomes of mechanical versus bioprosthetic aortic valve replacements. J Thorac Cardiovasc Surg 2015;149:1262-9.

13. Carnero-Alcazar M, Maroto-Castellanos LC, Hernandez-Vaquero D, et al. Isolated aortic valve replacement in Spain: national trends in risks, valve types, and mortality from 1998 to 2017. Rev Esp Cardiol (Engl Ed) 2021;74:700-7.

14. Moon TJ. Light and shadows of the Korean healthcare system. J Korean Med Sci 2012;27(Suppl):S3-6.

15. Song SO, Jung CH, Song YD, et al. Background and data configuration process of a nationwide population-based study using the Korean national health insurance system. Diabetes Metab J 2014;38:395403.

16. Bartus K, Sadowski J, Litwinowicz R, et al. Changing trends in aortic valve procedures over the past ten years-from mechanical prosthesis via stented bioprosthesis to TAVI procedures - analysis of 50,846 aortic valve cases based on a Polish National Cardiac Surgery Database. J Thorac Dis 2019;11:2340-9.

17. American College of Cardiology/American Heart Association Task Force on Practice Guidelines; Society of Cardiovascular Anesthesiologists; Society for Cardiovascular Angiography and Interventions, et al. ACC/AHA 2006 guidelines for the management of patients with valvular heart disease: a report of the American College of Cardiology/American Heart Association Task Force on Practice Guidelines (writing committee to revise the 1998 guidelines for the management of patients with valvular heart disease): developed in collaboration with the Society of Cardiovascular Anesthesiologists: endorsed by the Society for Cardiovascular Angiography and Interventions and the Society of Thoracic Surgeons. Circulation 2006;114:e84-231.

18. Nishimura RA, Otto CM, Bonow RO, et al. 2014 AHA/ACC guideline for the management of patients with valvular heart disease: a report of the American College of Cardiology/American Heart Association Task Force on Practice Guidelines. J Thorac Cardiovasc Surg 2014;148:e1-132.

19. Nishimura RA, Otto CM, Bonow RO, et al. 2017 AHA/ACC focused update of the 2014 AHA/ACC guideline for the management of patients with valvular heart disease: a report of the American College of Cardiology/American Heart Association Task Force on Clinical Practice Guidelines. Circulation 2017;135:e1159-95.

20. Falk V, Baumgartner H, Bax JJ, et al. 2017 ESC/EACTS guidelines for the management of valvular heart disease. Eur J Cardiothorac Surg 2017;52:616-64.

21. Otto CM, Nishimura RA, Bonow RO, et al. 2020 ACC/AHA guideline for the management of patients with valvular heart disease: a re- 
port of the American College of Cardiology/American Heart Association Joint Committee on Clinical Practice Guidelines. Circulation 2021;143:e72-227.

22. Takagi H, Mitta S, Ando T. Meta-analysis of valve-in-valve transcatheter versus redo surgical aortic valve replacement. Thorac Cardiovasc Surg 2019;67:243-50.

23. Al-Sarraf N, Thalib L, Hughes A, et al. Cross-clamp time is an independent predictor of mortality and morbidity in low- and high-risk cardiac patients. Int J Surg 2011;9:104-9.

24. Iino K, Miyata H, Motomura N, et al. Prolonged cross-clamping during aortic valve replacement is an independent predictor of postoperative morbidity and mortality: analysis of the Japan Cardiovascular Surgery Database. Ann Thorac Surg 2017;103:602-9.

25. Filip G, Litwinowicz R, Kapelak B, et al. Mid-term follow-up after suture-less aortic heart valve implantation. J Thorac Dis 2018;10: 6128-36.

26. Williams ML, Flynn CD, Mamo AA, et al. Long-term outcomes of sutureless and rapid-deployment aortic valve replacement: a systematic review and meta-analysis. Ann Cardiothorac Surg 2020;9:26579. 